\title{
On The Relationship Between Program Missions And Analytic Techniques In Evaluation of Mutually Exclusive Alternatives
}

\author{
Snehamay Khasnabis, Joseph Bartus, Emadeddin Alsaidi \\ Wayne State University/Michigan Department of Transportation/PARSONS
}

\begin{abstract}
$\underline{\text { Abstract }}$
The purpose of economic evaluation of project alternatives is to ensure that the project selected for implementation from a mutually exclusive set is the one with the highest benefits. This type of evaluation is often termed ex-ante analysis, conducted to identify the specific project where resources should be allocated. A number of analytic techniques may be used to evaluate mutually exclusive alternatives. Similarly, alternatives may be evaluated under different policy scenarios, or missions.
\end{abstract}

In this paper four analytic techniques are discussed. The Cost Effectiveness technique essentially identifies the project with the least cost per unit benefit, while the Benefit Cost ratio technique is directed toward designating the project with the highest benefit per unit cost, both at a specified interest rate. The Internal Rate of Return technique attempts to identify the project that provides the highest return to the investor within a specified project life. The Pay off Period technique on the other hand, helps to identify the project that provides a specified return to the investor in the fastest possible time frame. Three missions are also identified in the paper; Mission A, constrained resource perspective; Mission B, investment perspective; and Mission $\mathrm{C}$, face value perspective. Each mission can be paired with a specific analytic technique resulting in varying solutions in determining the best alternative. A case study is presented using the four analytic technique and three missions among a set of eight mutually exclusive highway safety alternatives.

Results show under compatible assumptions, and for a given program mission, the choice of the analytic technique does not affect the outcome of the evaluation. However, for a given analytic technique, the outcome of the evaluation may be affected by the choice of the program mission. These findings underscore the importance of defining the program mission at the outset, before actual economic analysis of alternatives is conducted. Even though the case study involves a highway safety project, the principles presented are relevant for all public projects (e.g. transit, airports, etc.) involving the investment of taxpayers resources. 


\section{Introduction}

The purpose of "pre-project" evaluation of highway safety projects is to ensure that the project selected for implementation from a set of mutually exclusive alternatives is the one with the highest benefits. Indeed, in a broader sense, the purpose is to make the most efficient allocation of society's resources in aiding social-decision making ${ }^{1}$. This type of evaluation is often termed ex-ante analysis, conducted to identify the specific project where resources should be allocated. This is to be contrasted from ex-post analysis, conducted on completion of the project to assess the degree to which the project actually "delivered" the expected services. The value of ex-post analysis is broader, designed to contribute to "learning" by the agencies concerned about the ultimate "worthwhileness" of such projects.

Any ex-ante evaluation is based on the premise that, in order for an alternative to be viable, the benefits to whomsoever they may accrue must exceed the estimated $\operatorname{costs}^{2}$. In reality, there can be a number of alternatives for which benefits may exceed cost. The question addressed in the paper is "How to identify the alternative with the highest benefit?" There may not be a simple answer to this seemingly straightforward question.

Rational decisions among alternatives should take into consideration all prospective consequences, tangible or intangible. In many cases, and certainly in the case of highway safety projects, there are uncertainties with the assessment of these consequences ${ }^{3,4,5}$. This feature of uncertainty adds one more dimension of complexity to the process of ex-ante evaluation ${ }^{6,7}$.

\section{$\underline{1.1 \text { Background Information }}$}

Within the conceptual framework of incorporating all costs and benefits during project evaluation, a number of analytic tools have been developed, each with a specific set of characteristics $^{8,9,10}$ :

- Cost Effectiveness (C/E) Technique

- Benefit Cost (B/C) Ratio Technique

- Internal Rate of Return (IRR) Technique, and

- Pay Off Period (PP) Technique

The four techniques identified are associated with four Measures of Effectiveness (MOE's) designed to reflect the degree to which a set of mutually exclusive alternatives are expected to meet their economic goals. The $(\mathrm{C} / \mathrm{E})$ technique essentially identifies the project with the least cost per unit benefit, while the $(\mathrm{B} / \mathrm{C})$ ratio technique is directed toward designating the project with the highest benefit per unit cost, both at a specified interest rate. The IRR technique attempts to identify the project that provides the highest return to the investor within a specified project life. The (PP) technique on the other hand, helps to identify the project that provides a specified return to the investor in the fastest possible time frame. The four MOE's are the $(\mathrm{C} / \mathrm{E})$ Index, $(\mathrm{B} / \mathrm{C})$ ratio, IRR and $(\mathrm{PP})$ for the four techniques. 
The selection of any one of the above four techniques for alternative evaluation/selection purposes depends upon a number of factors including the validity of assumptions, availability of data, and most important, the intended use of the results. While each of the four techniques has certain basic characteristics and limitations, under compatible assumptions, the selection of the optimum project is not generally affected by the choice of the analytic technique ${ }^{11}$. However, the selection may, under certain circumstances, depend upon the mission of the program. This will be demonstrated in the paper.

Note that the term "project" is used in this paper to denote a specific alternative selected for implementation from among a set of mutually exclusive entities. The term "program" is used to describe a combination of independent projects selected for implementation, using a process often termed as "Capital Budgeting Techniques"2. The focus of this paper is on evaluation of mutually exclusive alternatives, and not on Capital Budgeting Techniques.

\subsection{Purpose of the Paper}

The premise of ex-ante evaluation, as stated earlier is to select the project with the highest benefit. But "What exactly is the highest benefit?" and more importantly, "How is it to be measured?" These two questions must be answered at the outset, as these answers may significantly affect the selection of the optimum project. The purpose of this paper is two fold. First, a brief discussion of the theoretical foundation of the four techniques is presented. Second, the authors demonstrate that the mission of the program, under which public projects (e.g. Highway safety) are funded play a more important role than the technique used in the selection of the optimum project.

\section{Program Missions}

Generally, the mission of the program under which public projects are funded, can be classified under three broad categories:

- Mission A: To support the maximum number of independent projects, and select the optimum project from a set of mutually exclusive alternatives accordingly. Mission A represents the constrained resource viewpoint and is in recognition of the fact that resources available for public projects are generally far short of those needed to meet the demand, and hence public policies should be directed to "spread the wealth" by funding as many independent projects as possible. Thus, the object of maximization of the number of independent projects to be funded would necessarily result in selecting the least cost alternative from each mutually exclusive set. Adopting Mission A would result in the following ground rule:

"From a set of mutually exclusive alternatives, select the least cost project, with the stipulation that benefits must exceed cost." 
- Mission B: To use an investment viewpoint to select the optimum project from a set of mutually exclusive projects. Competition for dollars for other independent projects should not be a factor in this decision-making process. From a public policy perspective, projects should be treated strictly as an investment opportunity, and be directed to fetch the highest return to the tax-payer. Further, no alternative should be disqualified just because it is "too expensive". Indeed if a project is deemed "too expensive" at the outset, it should not be considered as part of the mutually exclusive set.

The procedure for incorporating Mission B into the decision making process is often termed as the "Defender-Challenger" technique ${ }^{2}$. The process is initiated by rank ordering the alternatives from the least cost to the highest cost projects followed by a pairwise comparison of alternatives where alternatives with higher investment costs are required to justify their selection through marginal cost analysis. Alternatives that cannot be justified are eliminated, and the pairwise comparison is continued until the most expensive alternative is analyzed. Once again the critical part of this technique is the rank ordering of the alternatives by their cost at the out set. The use of Mission $\mathrm{B}$ would result in the following ground rule:

"From a set of mutually exclusive alternatives, select the project that provides the highest return to the investor."

- Mission C: Neither investment, nor constrained resources should be a factor; project selection should be on the basis of the "face-value" of the MOE's generated during the evaluation process. Adopting Mission $\mathrm{C}$ would result in the following ground rule:

"From a set of mutually exclusive alternatives, select the project with the highest amount of benefit per unit cost."

Note that the three missions stated above are generally not explicitly stated as such in any policy document. But the authors feel that the three cover the practical range of possibilities that underline the funding of public projects. While each of the three missions may be perfectly valid and reasonable in its own right, the selection of the optimum alternative may vary with the mission. Note the three ground rules can be looked upon as "generic" rules. When associated with a given analytic technique, more "specificity" can be incorporated into the ground rules, resulting in specific decision rules. This is explained in the next section.

\section{The Four Analytic Techniques}

A brief theoretical foundation of the four techniques is presented below to provide continuity with the case study demonstration. The following symbols are used in the discussion.

$$
(\mathrm{A} / \mathrm{F})=\text { Sinking Fund Factor }
$$




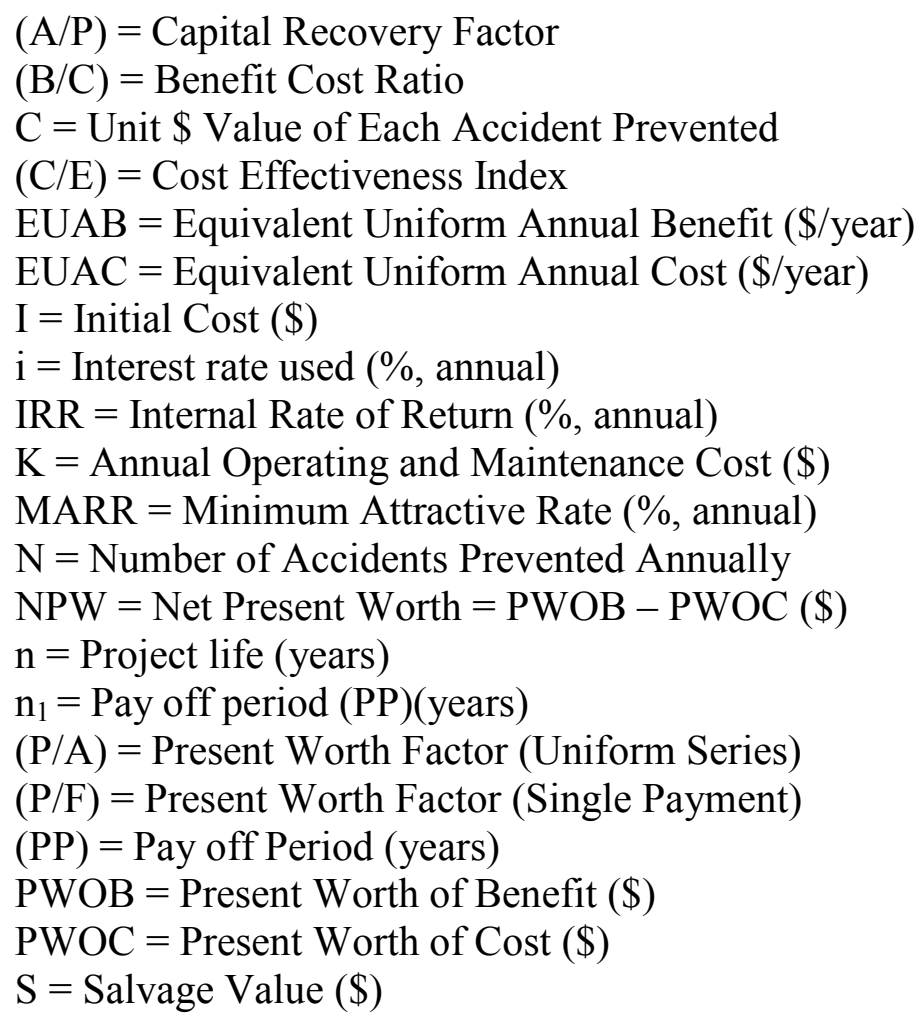

\subsection{Cost Effectiveness (C/E) Technique}

The principle of Cost Effectiveness $(\mathrm{C} / \mathrm{E})$ techniques is based upon the premise that the alternative that costs the least to derive one unit of benefit is considered to be most cost effective. For the highway safety project case, this should be the alternative that costs the least to prevent a highway accident (of a specific type). The algorithm is as follows:

$(\mathrm{C} / \mathrm{E})=\mathrm{EUAC} / \mathrm{N}$ (1), when

$\mathrm{EUAC}=\mathrm{I}(\mathrm{A} / \mathrm{P})+\mathrm{K}-\mathrm{S}(\mathrm{A} / \mathrm{F})(\$ /$ year $)$

$\mathrm{N}=$ Number of Accidents Prevented Annually

$(\mathrm{C} / \mathrm{E})=$ Cost Effective Index (Dollars spent to prevent each accident $)$

The $(\mathrm{C} / \mathrm{E})$ technique only provides comparative MOE's of the alternatives being tested and can be used to rank alternatives in order of their desirability. It cannot be used to determine if the benefits of any alternative "outweigh" its costs. Thus, a project designated as the most cost effective, may not necessarily be cost efficient. The advantage of this technique is that, it is not necessary to attach a dollar value to the benefits, a task often considered the most difficult one in evaluating public projects, such as highway safety projects ${ }^{12,13,14}$. Because no dollar value is attached in quantifying savings in accident, only Mission C is relevant for the $(\mathrm{C} / \mathrm{E})$ technique. The decision rule can be formalized as:

\section{Mission C:}


* Select the alternative with the lowest (C/E) Index

\section{$\underline{3.2}$ Benefit Cost $(B / C)$ Technique}

The $(\mathrm{B} / \mathrm{C})$ ratio is one of the more common techniques used in project evaluation, primarily because of its ease of interpretation ${ }^{12,15}$. (B/C) ratio is simply a measure of the number of units of benefits that the project is expected to provide per unit cost. The algorithm used is:

$(\mathrm{B} / \mathrm{C})=$ Benefit $/$ Cost $=$ EUAB $/$ EUAC, where

EUAC can be computed as shown in equation 2. The computation of EUAB can be problematic, particularly in public projects, a detailed discussion of which is beyond the scope of this paper ${ }^{16}$. In the specific highway safety project case, EUAB can be computed as:

$\mathrm{EUAB}=\mathrm{N} \times \mathrm{C}$ (3), where

$\mathrm{N}=$ Number of Accidents (of a particular type) Prevented Annually

$\mathrm{C}=$ Unit $\$$ Value of Each Accident Prevented, so that

$(\mathrm{B} / \mathrm{C})=(\mathrm{N} \times \mathrm{C}) / \mathrm{EUAC}$

In the evaluation process, all projects with $(\mathrm{B} / \mathrm{C})$ ratios exceeding unity are considered viable. The selection of the best project will depend on the mission of the program. These decisions rules can be formalized as:

Mission A:

- Select the alternative with the least EUAC, provided $(B / C)_{\text {absolute }} \geq 1.00$

Mission B:

- Select the alternative with the highest investment, subject to

$(B / C)_{\text {absolute }} \geq 1.00$, and

$(B / C)_{\text {marginal }} \geq 1.00$

\section{Mission C:}

- Select the alternative with the highest $(B / C)_{\text {absolute }}$ value subject to $(B / C)_{\text {absolute }} \geq 1.00$

\subsection{Internal Rate of Return (IRR) Technique}

The IRR technique is used quite frequently, in spite of difficulties in computation ${ }^{16,17}$. Unlike the previous two cases, where an interest rate is assumed at the outset, the IRR technique requires the computation of the interest (or the yield) that the project is expected to return to the investor. The algorithm is based upon the premise that the IRR is the interest rate at which the Net Present Worth (NPW) of the project equals zero, and can be written as:

Set NPW $=0$, i.e. 
$\mathrm{PWOB}=\mathrm{PWOC}$, i.e.

$\mathrm{N} \times \mathrm{C} \times(\mathrm{P} / \mathrm{A})=\mathrm{I}+\mathrm{K}(\mathrm{P} / \mathrm{A})-\mathrm{S}(\mathrm{P} / \mathrm{F})$

A theoretical solution of equation (5) to derive the appropriate interest can be computationally complex. An empirical solution may be attained using a trial and error process, by systematically altering the interest rate until a convergence is found. All projects yielding an IRR, exceeding an initially specified Minimum Attractive Rate of Return (MARR) become viable. The decision rules can be formalized as:

\section{Mission A:}

- Select the least expensive alternative, provided $I R R_{\text {absolute }} \geq M A R R$

\section{Mission B:}

- Select the alternative with the highest investment, subject to

$$
\begin{aligned}
& I R R_{\text {absolute }} \geq M A R R, \text { and } \\
& I R R_{\text {marginal }} \geq M A R R
\end{aligned}
$$

\section{Mission C:}

- Select the alternative with the highest $I R R_{\text {absolute, }}$ provided $I R R_{\text {absolute }} \geq M A R R$

Note: MARR, is used to judge the attractiveness of proposed investments, and represents a "bench-mark" yield, below which all investment proposals are to be considered unattractive. The determination of MARR is normally a policy issue and criteria for setting it are quite varied $^{2}$.

\subsection{Pay Off Period (PP) Technique}

The (PP) technique is used when "the time taken by the project to pay for itself" is the desired answer. The algorithm used is the same as the one used in the IRR technique (equation 5). However, the solution strategy is different. In this case, an interest rate must be assumed (usually the MARR or higher), and the value of $n_{1}$, (Pay off Period) is sought by trial and error, until equation (5) is satisfied.

If $\mathrm{n}_{1}>\mathrm{n} \quad$ Reject

If $\mathrm{n}_{1} \leq \mathrm{n} \quad$ Accept

The rationale is if a project pays for itself earlier than the period the project is expected to last, it essentially provides "free" service to the investor for the difference between the two periods. If on the other hand, it takes longer to pay for itself, the additional period is a "liability" to the investor. The decision rules can be formalized as follows:

\section{Mission A:}

- Select the alternative with the least investment, subject to $n_{1} \leq n$ 


\section{Mission B:}

- Select the alternative with the highest investment subject to:

$\left(n_{1}\right)$ absolute $\leq n$

$\left(n_{1}\right)_{\text {marginal }} \leq n$

Mission C:

- Select the alternative with the lowest $\left(n_{1}\right)$ absolute value provided

$\left(n_{1}\right)$ absolute $\leq n$

Note: The concepts of (IRR) marginal and $(\mathrm{B} / \mathrm{C})_{\text {marginal }}$ are widely used as a decision making tools. However, the concept of marginal Pay off Period, $\left(\mathrm{n}_{1}\right)$ marginal is uncommon, partly because of the Pay off Period technique itself is seldom used as a decision making tool. However, the authors used the same concept used in (IRR) marginal and $(\mathrm{B} / \mathrm{C})_{\text {marginal }}$ analysis, to compute the marginal Pay off Period. The interpretation of marginal Pay off Period is the number of years taken by the extra-investment to pay for itself at a specified interest rate.

\section{Case Study Demonstration}

The relationship between the program missions and project selection is demonstrated through a hypothetical case study comprising a total of eight mutually exclusive highway safety alternatives. The problem statement is as follows:

The initial investment required for alternatives 1 through 8 are: $\$ 600 \times 10^{3}, \$ 700 \times 10^{3}, \$ 800 \times 10^{3}$, $\$ 1000 \times 10^{3}, \$ 1200 \times 10^{3}, \$ 1400 \times 10^{3}, \$ 1500 \times 10^{3}$ and $\$ 1600 \times 10^{3}$, respectively. Based upon the use of Accident Reduction Factors, the expected number of accidents likely to be prevented per year is estimated as 5, 6.53, 7.6, 9.87, 12.4, 13, 15.06, and 15.27 respectively, for alternatives $1,2,3$, 4, 5, 6, 7 and 8 (Note: There is a large body of literature on Accident Reduction Factors, a detailed discussion of which is beyond the scope of the paper ${ }^{8,10}$ ). Annual operating and maintenance cost is assumed to be $5 \%$ of the initial investment. Expected project life is 15 years, and salvage value is assumed to be zero for all the alternatives. MARR is assumed to be $10 \%$, and an interest rate of $10 \%$ is assumed in amortizing the investment cost. The "worth" of each accident saved is assumed as $\$ 21 \times 10^{3}$.

While the procedure for Mission A and Mission C are straightforward for Mission B, the procedure calls for developing two sets of $\mathrm{MOE}$ 's, i.e. $\mathrm{MOE}_{\text {absolute }}$ and $\mathrm{MOE}_{\text {marginal }}$. The Defender-Challenger analysis requiring pair-wise comparisons between alternatives in increasing order of investment was adapted from Grant et al. for Mission $\mathrm{B}^{2}$.

\section{$\underline{4.1(C / E)}$ Technique}

Results of $(\mathrm{C} / \mathrm{E})$ technique are presented in Table 1 . Line 5 shows the $(\mathrm{C} / \mathrm{E})$ values for each alternative, computed using the formulations presented earlier. Since a dollar-value is not attached to accidents saved, neither Mission A nor B is applicable. Using Mission C, the most cost effective alternative is 5 , with a $(\mathrm{C} / \mathrm{E})$ value of $\$ 17,560$, indicating that for alternative 5 , the 
cost of saving each accident is $\$ 17,560$. Alternative 5 should be selected by Mission $\mathrm{C}$, as it provides the lowest $(\mathrm{C} / \mathrm{E})$ Index among all alternatives. The concept of marginal return on the extra investment is not applicable for the $(\mathrm{C} / \mathrm{E})$ technique.

TABLE 1 Analysis of Eight Mutually Exclusive Alternatives Using the (C/E) Technique

\begin{tabular}{|c|c|c|c|c|c|c|c|c|}
\hline \multirow[b]{2}{*}{ Economic Analysis Data } & \multicolumn{8}{|c|}{ Alternatives Listed In Increasing Order of Investment } \\
\hline & 1 & 2 & 3 & 4 & 5 & 6 & 7 & 8 \\
\hline 1. Investment $(\$ 1000)$ & 600 & 700 & 800 & 1000 & 1200 & 1400 & 1500 & 1600 \\
\hline 2. Annual Operating and Mant. Cost (\$1000/yr) & 30 & 35 & 40 & 50 & 60 & 70 & 75 & 80 \\
\hline 3. EUAC (\$1000/yr) (Eqn. 2) & 108.9 & 127 & 145.2 & 181.5 & 217.8 & 254.1 & 272.2 & 290.4 \\
\hline 4. Number of Accidents Saved Annually (N) & 5 & 6.53 & 7.6 & 9.87 & 12.4 & 13 & 15.06 & 15.27 \\
\hline 5. (C/E) value (\$1000/Accident) & 21.78 & 19.45 & 19.1 & 18.38 & $17.56^{*}$ & 19.55 & 18.07 & 19.02 \\
\hline
\end{tabular}

${ }^{*}$ Mission C - Select alternative 5

\subsection{Benefit Cost Ratio (B/C) Technique}

Table 2 shows the results of applying the $(\mathrm{B} / \mathrm{C})$ ratio for the eight alternatives. The $(\mathrm{B} / \mathrm{C})$ absolute and $(\mathrm{B} / \mathrm{C})_{\text {marginal }}$ figures are shown in lines 6 and 11 respectively.

TABLE 2 Analysis of Eight Mutually Exclusive Alternatives Using the (B/C) Ratio Technique

\begin{tabular}{|c|c|c|c|c|c|c|c|c|}
\hline 1. Investment (\$1000) & 600 & 700 & 800 & 1000 & 1200 & 1400 & 1500 & 1600 \\
\hline 3. EUAC (\$1000/yr) (Eqn. 2) & 108.9 & 127 & 145.2 & 181.5 & 217.8 & 254.1 & 272.2 & 290.4 \\
\hline 4. Number of Accidents Saved Annually (N) & 5 & 6.53 & 7.6 & 9.87 & 12.4 & 13 & 15.06 & 15.27 \\
\hline 5. EUAB ( $\$ 1000 / y r)$ (Eqn. 3) @ $\$ 21,000 /$ Accident saved & 105 & 137 & 160 & 207 & 260 & 273 & 316 & 321 \\
\hline 8. Compare with Defender & & & 2 & 3 & 4 & 5 & 5 & 7 \\
\hline 9. Incremental EUAC (\$1000/yr) & & & 18.2 & 36.3 & 36.3 & 36.3 & 54.4 & 18.2 \\
\hline 10. Incremental EUAB ( $\$ 1000 / y r)$ & & & 23 & 47 & 53 & 13 & 56 & 5 \\
\hline 11. $(B / C)_{\text {marginal }}$ & & & 1.26 & 1.29 & 1.46 & 0.36 & $1.03^{\star \star}$ & 0.33 \\
\hline
\end{tabular}

${ }^{*}$ Mission A - Select alternative 2

**Mission B - Select alternative 7

${ }^{\star * \star *}$ Mission C - Select alternative 5

Based upon a review of the data, project selection is as follows:

\section{Mission A:}

- Select alternative 2, as this is the least expensive project with a $(B / C)_{\text {absolute }}$ ratio exceeding unity. 


\section{Mission B:}

- Select alternative 7, as this is the most expensive project, for which both the $(B / C)_{\text {absolute }}$ and $(B / C)_{\text {marginal }}$ values exceed unity. It should be noted that during the Defender-Challenger analysis, alternative 6 , with a $(\mathrm{B} / \mathrm{C})_{\text {marginal }}$ ratio of 0.36 , is eliminated from further consideration, so that alternative 5 continues as the defender, to be challenged by alternative 7. Further, alternative 8 with a $(\mathrm{B} / \mathrm{C})_{\text {marginal }}$ of 0.33 is unsuccessful in challenging alternative 7 , leaving alternative 7 as the "winner". Note that alternative 7 is the highest investment alternative for which both the $(\mathrm{B} / \mathrm{C})_{\text {absolute }}$ and $(\mathrm{B} / \mathrm{C})_{\text {marginal }}$ exceed unity.

\section{Mission C:}

- Select alternative 5, as the $(B / C)_{\text {absolute }}$ ratio is maximized at 1.19

\subsection{Internal Rate of Return (IRR) Technique}

Results are presented in Table 3, with the (IRR) absolute and (IRR) marginal values shown in lines 4 and 9 respectively.

TABLE 3 Analysis of Eight Mutually Exclusive Alternatives Using the (IRR) Technique

\begin{tabular}{|c|c|c|c|c|c|c|c|c|}
\hline \multirow[b]{2}{*}{ Economic Analysis Data } & \multicolumn{8}{|c|}{ Alternatives Listed In Increasing Order of Investment } \\
\hline & 1 & 2 & 3 & 4 & 5 & 6 & 7 & 8 \\
\hline 1. Investment $(\$ 1000)$ & 600 & 700 & 800 & 1000 & 1200 & 1400 & 1500 & 1600 \\
\hline 2. Annual Operating and Maint. Cost $(\$ 1000 / y r)$ & 30 & 35 & 40 & 50 & 60 & 70 & 75 & 80 \\
\hline 3. EUAB (\$1000/yr) & 105 & 137 & 160 & 207 & 260 & 273 & 316 & 321 \\
\hline 4. (IRR) $)_{\text {absolute }}(\%)$, (Eqn. 5) & 9 & $11.5^{*}$ & 12.5 & 13 & $14.5^{\star \star \star}$ & 11.5 & $13.5^{\star \star}$ & 12.5 \\
\hline 5. $(\mathrm{IRR})_{\text {absolute }} \geq \mathrm{MARR}$ of $10 \%$ ? & $\mathrm{N}$ & $\mathrm{Y}$ & Y & Y & $\mathrm{Y}$ & $\mathrm{Y}$ & Y & Y \\
\hline 6. Compare with Defender & & & 2 & 3 & 4 & 5 & 5 & 7 \\
\hline 7. Net Incremental Investment $(\$ 1000)$ & & & 100 & 200 & 200 & 200 & 300 & 100 \\
\hline 8. Net Incremental Benefit $(\$ 1000 / y r)^{\star \star \star *}$ & & & 18 & 37 & 43 & 3 & 41 & 0 \\
\hline 9. $(\mathrm{IRR})_{\text {marginal }}(\%)$ & & & 16 & 17 & 20 & 0.5 & $10.5^{\star *}$ & 0 \\
\hline 10. $(I R R)_{\text {marginal }} \geq M A R R$ ? & & & Y & Y & Y & $\mathrm{N}$ & Y & $\mathrm{N}$ \\
\hline 11. Defender & & & 3 & 4 & 5 & 5 & 7 & 7 \\
\hline
\end{tabular}

${ }^{*}$ Mission A - Select alternative 2

${ }^{* *}$ Mission B - Select alternative 7

${ }^{* * *}$ Mission $\mathrm{C}$ - Select alternative 5

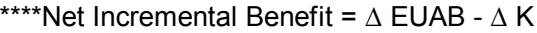

$\triangle \mathrm{EUAB}=$ Incremental EUAB

Based upon a review of the data, project selection is as follows:

\section{Mission A:}

- Select alternative 2, being the least expensive alternative with an (IRR) absolute exceeding the MARR of $10 \%$

\section{Mission B:}

- Select alternative 7, being the most expensive alternative, with both $(\text { IRR })_{\text {absolute }}$ and $(\text { IRR })_{\text {marginal }}$ exceeding $10 \%$. 
Note that alternative 6 , with an (IRR) marginal of less than $0.5 \%$ is eliminated from further consideration, so that alternative 5 continues to be the defender, to be challenged by alternative 7. Further, alternative 8 , with an (IRR) marginal of $0 \%$ is unsuccessful in challenging alternative 7 , leaving alternative 7 as the "winner". Alternative 7 is selected because it is the highest investment alternative for which both the (IRR) absolute and (IRR) marginal exceed $10 \%$.

\section{Mission C:}

- Select alternative 5 that provides the highest (IRR) absolute of $14.5 \%$

\subsection{Pay off Period (PP) Technique}

Results are presented in Table 4, with the (PP) $)_{\text {absolute }}$ and (PP) marginal values shown in lines 4 and 9 respectively.

TABLE 4 Analysis of Eight Mutually Exclusive Alternatives Using the (PP) Technique

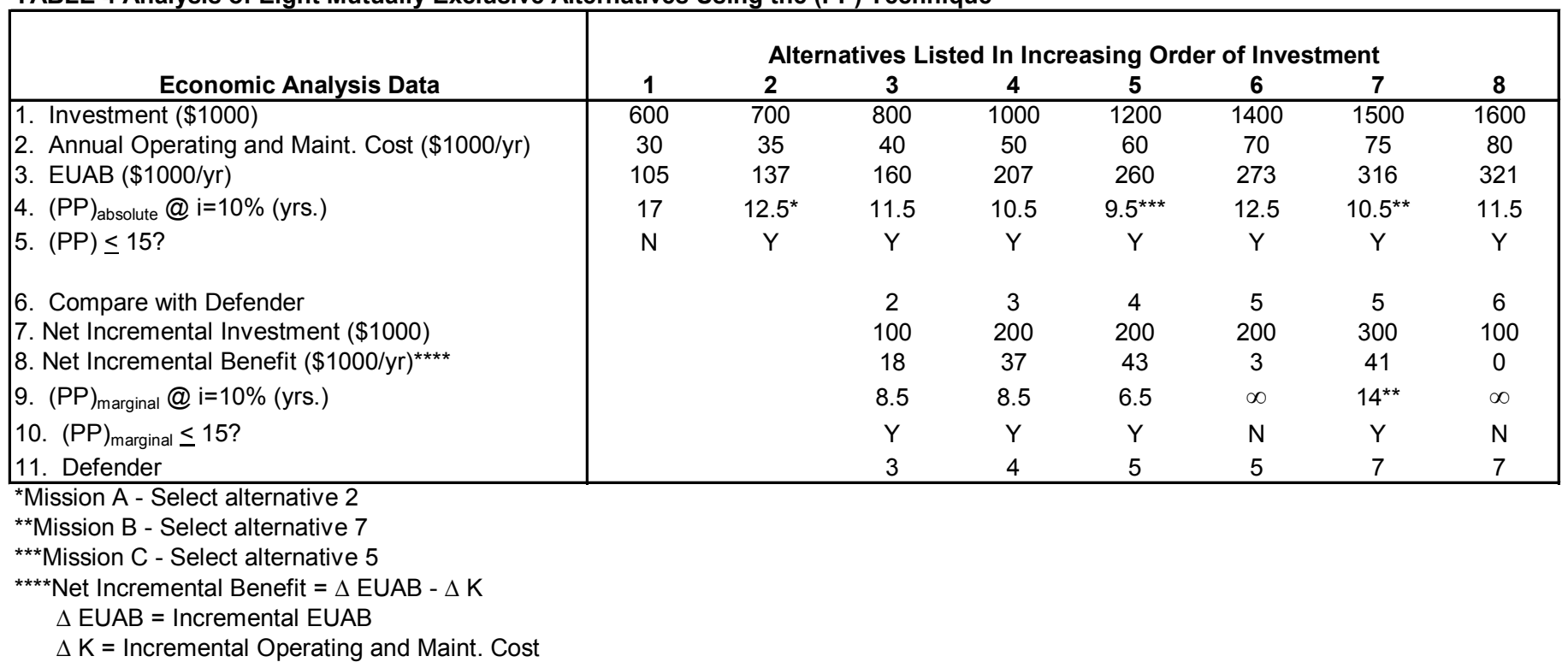

Based upon a review of the data, project selection is as follows:

\section{Mission A:}

- Select alternative 2, as the least expensive alternative, with a (PP) absolute value less than 15 years

\section{Mission B:}

- Select alternative 7 as the most expensive alternative, with both $(P P)_{\text {absolute }}$ and $(P P)_{\text {marginal }}$ values less than 15 years.

Note that for alternatives 6 and 8, the (PP) marginal values approach infinity, indicating that for these two alternatives, it will take "forever" to pay for the extra investments through savings in 
accidents. Alternative 7 should be selected as it is the highest investment alternative for which both (PP) $)_{\text {absolute }}$ and $(\mathrm{PP})_{\text {marginal }}$ are less than 15 years.

\section{Mission C:}

- Select alternative 5, with the lowest (PP) absolute value among all eight alternatives.

\subsection{Summary of the Results}

A summarized version of the ground rules for the three missions and the four analytic techniques is presented in the form of a matrix in Table 5. Results of the case study applications are also presented in the respective cells of the matrix.

TABLE 5 Decision Rules for Selecting Optimum Project for Mutually Exclusive Alternatives and Results of Case Study Application

\begin{tabular}{|c|c|c|c|}
\hline Analytic Technique & $\begin{array}{c}\text { Mission A (Constrained } \\
\text { Resource) }\end{array}$ & Mission B (Investment) & Mission C (Face-value) \\
\hline (C/E) Technique & NA & NA & $\begin{array}{l}\text { Select the alternative with the } \\
\text { least }(C / E) \text { Index } \\
\text { Select Alternative } 5\end{array}$ \\
\hline $\begin{array}{c}\text { Benefit Cost }(B / C) \text { Ratio } \\
\text { Technique }\end{array}$ & $\begin{array}{l}\text { Select the least expensive } \\
\text { alternative subject to: } \\
(\mathrm{B} / \mathrm{C})_{\text {absolute }} \geq 1.00 \\
\text { Select Alternative } 2\end{array}$ & $\begin{array}{l}\text { Select the most expensive } \\
\text { alternative subject to: } \\
(B / C)_{\text {absolute }} \geq 1.00 \\
(B / C)_{\text {marginal }} \geq 1.00 \\
\text { Select Alternative } 7\end{array}$ & $\begin{array}{l}\text { Select the alternative with the } \\
\text { highest }(B / C)_{\text {absolute }} \text { subject to: } \\
(\mathrm{B} / \mathrm{C})_{\text {absolute }} \geq 1.00 \\
\text { Select Alternative } 5\end{array}$ \\
\hline $\begin{array}{l}\text { Internal Rate of Return } \\
\text { (IRR) Technique }\end{array}$ & $\begin{array}{l}\text { Select the least expensive } \\
\text { alternative subject to: } \\
I_{R R_{\text {absolute }} \geq \mathrm{MARR}} \\
\text { Select Alternative } 2\end{array}$ & $\begin{array}{l}\text { Select the most expensive } \\
\text { alternative subject to: } \\
I R_{\text {absolute }} \geq \mathrm{MARR} \\
\mathrm{IRR}_{\text {marginal }} \geq \mathrm{MARR} \\
\text { Select Alternative } 7\end{array}$ & $\begin{array}{l}\text { Select the alternative with the } \\
\text { highest IRR absolute subject to: } \\
\qquad I_{\text {R }} \text { absolute } \geq \mathrm{MARR} \\
\text { Select Alternative } 5\end{array}$ \\
\hline $\begin{array}{l}\text { Pay off Period (PP) } \\
\text { Technique }\end{array}$ & $\begin{array}{l}\text { Select the least expensive } \\
\text { alternative subject to: } \\
\qquad\left(\mathrm{n}_{1}\right)_{\text {absolute }} \leq \mathrm{n} \\
\text { Select Alternative } 2\end{array}$ & $\begin{array}{l}\text { Select the most expensive } \\
\text { alternative subject to: } \\
\qquad \begin{array}{l}\left(\mathrm{n}_{1}\right)_{\text {absolute }} \leq \mathrm{n} \\
\left(\mathrm{n}_{1}\right)_{\text {marginal }} \leq \mathrm{n}\end{array} \\
\text { Select Alternative } 7\end{array}$ & $\begin{array}{l}\text { Select the alternative with the } \\
\text { least }\left(n_{1}\right)_{\text {absolute }} \text { value subject to: } \\
\qquad\left(\mathrm{n}_{1}\right)_{\text {absolute }} \leq \mathrm{n} \\
\text { Select Alternative } 5\end{array}$ \\
\hline
\end{tabular}

Table 5 shows that for a given mission, the selection of the project from a set of mutually exclusive alternatives is independent of the analytic technique used. In other words, the choice of the analytic technique does not affect the selection of the project. For example, for Mission A, the alternative selected is 2 , independent of the analytic technique. However, the selection of the project depends upon the program mission. For Mission A, the project selected is alternative 2, 
while for Mission B, it is alternative 7. The corresponding selection for Mission $\mathrm{C}$ is alternative 5 .

The above results underscore the importance of defining the program mission at the very outset of the planning process, before actual ex-ante evaluation is conducted. It will be improper, in the opinion of the authors to select a specific alternative first, and identify the mission that "fits" the solution.

\section{Conclusions and Recommendations}

The purpose of this paper is to present a broad overview of the different analytic techniques for ex-ante evaluation of mutually exclusive highway safety improvement alternatives and how the outcome of the evaluation may be affected by the selection of a program mission. Four analytic techniques are discussed: Cost-Effectiveness $(\mathrm{C} / \mathrm{E})$, Benefit-Cost $(\mathrm{B} / \mathrm{C})$ ratio, Internal Rate of Return (IRR), and Pay off Period (PP). The authors identify three likely missions within the broader context of a highway safety "program", where a program is the conglomerate of a number of projects, each project duly selected from a set of mutually exclusive alternatives, using one of the four techniques. The three missions identified are: Mission A (Constrained Resource perspective), Mission B (Investment Perspective), and Mission C (Face-value perspective). Even though these missions may not be explicitly stated as policy directives, the authors feel that they cover the broad range of possibilities that underline public funding issues.

Following a discussion of the theoretical foundation of the four techniques, the authors demonstrate the interrelationship between the four techniques and the three missions through a set of eight mutually exclusive highway safety improvement alternatives. The major conclusions of the paper are:

- Under compatible assumptions and for a given program mission, the choice of the analytic technique does not appear to affect the outcome of the evaluation. In other words, the project finally selected is independent of the analytic technique used, given a specific program mission. The choice of the analytic technique should however, be based on the intended use of the results and availability of data.

If for example, estimation of the amount of benefit per unit cost incurred is the desired result, the $(\mathrm{B} / \mathrm{C})$ ratio should be used. If, on the other hand, the analysis is directed toward assessing the return on the investment, the IRR technique should be used. Similarly, if the analyst is interested in knowing, how long it takes for the project to pay for itself, (and how this period might compare with the life of the project), the (PP) technique should be used. Lastly, if the intended use of the results is simply to identify the project with the least cost per unit benefit, the $(\mathrm{C} / \mathrm{E})$ technique should be the one used. The $(\mathrm{C} / \mathrm{E})$ technique has however, a serious limitation. Since no dollar value is attached to the benefit, the project selected as the most cost effective may not necessarily be cost efficient, in that the investment cost may not necessarily be "recovered" by way of the benefits generated. 
- The authors also demonstrate that for a given analytic technique, the outcome of the evaluation may be affected by the choice of the program mission. In the case study presented, the constrained resource perspective, (Mission A), the investment perspective (Mission B), and the Face value perspective (Mission C) resulted in the selection of different projects, for the same analytic technique used. It is however, conceivable, that in another case all the three missions may result in the same outcome.

- The above finding underscores the importance of defining the program mission at the outset, before actual economic analysis of alternatives is conducted. While each of the three missions can have a "rationale" in its own right, the fact that the choice of the mission may affect the final outcome, makes it all the more important, that the program mission be defined first, and the project selected accordingly.

- Although the case study deals with highway safety alternatives, the principles presented in this paper are relevant for all public projects where the object is to make the most prudent investment of taxpayers scarce resources. The process of "alternative analysis" is common not only in highway safety programs, but also with transit investment, airports, environmental projects, and similar infrastructure development involving public dollars. As in the case of highway safety, the program missions may significantly affect the outcome of evaluation, and hence the investment of tax-payers resources in public projects.

\section{List of References}

1. Boardman, A., Greenberg, D.H., Vining, A.R., and Weimer, D. K., "Cost Benefit Analysis: Concepts and Practice," Prentice Hall, NJ 1996.

2. Grant, E.L., Ireson, W.G., and Lavenworth, R.S., "Principles of Engineering Economy," John Wily and Sons, $8^{\text {th }}$ ed. NY 1990.

3. "The Evaluation of Highway Traffic Safety Programs," US Department of Transportation, NHTSA, 1977.

4. NCHRP Report 197, "Cost and Safety Effectiveness of Highway Design Elements", by Roy Jorgensten Assoc., Inc., National Research Council, 1978.

5. NCHRP Report 162, "Methods For Evaluation Highway Safety Improvements", by J.C. Laughland, et al., National Research Council, 1975.

6. Datta, T.K., Bowman, B.L., Opiela, K.S., "Evaluation of Highway Safety Projects Using Quality Control Techniques" TRB Record 672, 1978.

7. Zegeer, C.V., Deen, R.C., "Identification of Hazardous Location on City Streets", Traffic Quarterly, 1977. 
8. "Highway Safety Evaluation: Procedural Guide," Report for the Federal Highway Safety Administration, Prepared by Goodell Grivas, Inc., Southfield, MI 48075, March 1981

9. "Highway Safety Improvement Program", Report for the Federal Highway Administration, Prepared by Goodell Grivas, Inc., Southfield, MI 1981 (FHWA-TS-81-218)

10. “Accident Research Manual”, University of North Carolina-Highway Safety Research Center, 1980.

11. Khasnabis, S., and Bartus, J., "The Choice of An Analytical Technique for Economic Evaluation of Highway Safety Projects". Proceedings 2003 American Society for Engineering Education (ASEE). Conference, Nashville, TN, June 2003.

12. Mak, K.K., Sicking, D.L., and Zimmerman, K., "Roadside Safety Analysis Program: A Cost Effectiveness Analysis Procedure," Transportation Research Record 1647, National Research Council, Washington, D.C., 1998, pp 67-74.

13. "The Cost of Highway Crashes, "Report for the Federal Highway Administration (FHWA-RD-9-055), U.S. Department of Transportation, McLean, VA, 1991.

14. Winfrey, R., "Traffic Accident Costs in Economic Analysis", Report for the Highway Users Federation for Safety and Mobility, Nov. 1971.

15. Khasnabis, S., Rudraraju, R.K. and Baig, M.F., "Economic Evaluation of Signal Preemption Projects," Transportation Engineering Journal of the American Society of Civil Engineers, Vol 125, No. 2 pp 160-167, March 1999.

16. Khasnabis, S., Naseer, M., Baig, M.F. and Opiela, K.S., "Roadside Safety Analysis Program As a Tool for Economic Evaluation of Roadside Safety Projects," Transportation Research Record 1690, pp 31-41, Journal of the Transportation Research Board, 1999.

17. Khasnabis, S., Opiela, K.S., and Arbogast, R.G., "Economic Evaluation of Development Projects along Transportation Right of Way", Transportation Engineering Journal of ASCE, Vol. 108, TE 1, pp 51-70, 1982. 